\title{
Ultrasonographic evaluation of abdominal wall fat index, carotid intima-media thickness and plaque score in obstructive sleep apnea syndrome
}

\author{
Nurcan Çetin', İdil Güneş Tatar'1, Melike Yüceege², Onur Ergun', Baki Hekimoğlu1
}

${ }^{1}$ Department of Radiology, ${ }^{2}$ Department of Pulmonary Diseases, University of Health Sciences, Dışkapı Yıldırım Beyazit Training and Research Hospital, Ankara, Turkey

\begin{abstract}
Aims: Obstructive sleep apnea syndrome (OSAS) is strongly related with increased risk of cardiovascular diseases and visceral obesity. Abdominal wall fat index (AFI) is an indicator of visceral fat accumulation determined by ultrasonography (US). Carotid intima-media thickness (C-IMT) and carotid plaque score (C-PS) are the indicators of cardiovascular risk. The aim of this study was to investigate the relation between OSAS and AFI, C-IMT or C-PS. Materials and methods: One-hundred and four subjects (31 females, 73 males) between 23-73year-old, candidate for polysomnography (PSG) with suspect of

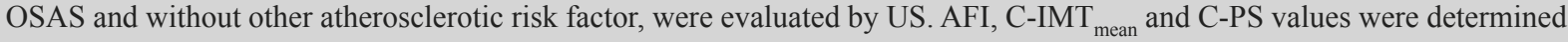
and the subjects were grouped according to their apnea-hypopnea index (AHI) values as follows: no OSAS $(<5)$, mild OSAS (5-15), moderate OSAS (15-30) and severe OSAS ( $>30)$. Results: There was a statistically significant correlation between

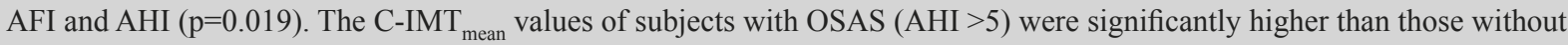
OSAS $(\mathrm{AHI}<5)(\mathrm{p}=0.035)$. C-PS was not correlated with AHI $(\mathrm{p}=0.345)$ and also there was not a statistically significant difference between OSAS groups in terms of C-PS $(\mathrm{p}=0.775)$. Conclusions: This study revealed that AFI correlates with AHI and C-IMT increases in OSAS. The two parameters could be used as indicators of risk of metabolic disorders and atherosclerotic diseases in subjects with sleep apnea in the future.
\end{abstract}

Keywords: ultrasonography; obstructive sleep apnea syndrome; abdominal wall fat index; carotid intima-media thickness; carotid plaque score

\section{Introduction}

Obstructive sleep apnea syndrome (OSAS) is a disease characterized by repetitive episodes of total or partial obstruction of upper airway and related hypopnea and

Received 17.03.2019 Accepted 04.07.2019

Med Ultrason

2019, Vol. 21, No 4, 422-426

Corresponding author: Nurcan Çetin, M.D.

Dışkapı Yıldırım Beyazıt Eğitim ve Araştırma

Hastanesi, Radyoloji Kliniği, Ziraat Mah.

Şehit Ömer Halisdemir Cad.

06110 Dışkapı-Altındağ/Ankara/Türkiye

Phone: +90 3125962617

E-mail: mdnurcan@hotmail.com apnea attacks during sleep [1,2]. Common complaints are fragmentation of sleep, snore, daytime somnolence and mouth dryness after awakening [1-3]. The prevalence of OSAS is $2-5 \%$ and $3-7 \%$ in middle-aged women and men, respectively [4-7]. Obesity is the prominent risk factor of OSAS $[8,9]$. The positive diagnosis of OSAS relay on the presence five or more obstructive apneas and/or hypopneas per hour of the sleep (apnea-hypopnea index) along polysomnography in a subject with symptoms of OSAS [10].

OSAS was related with metabolic disorders such as dyslipidemia and diabetes mellitus [11-14] and recently a relation between visceral fat deposition and severity of OSAS was reported $[13,15]$. Increased visceral fat seems 
to be a key factor for metabolic syndrome and OSAS. At this point, a need for a new indicator to demonstrate visceral fat deposition in OSAS patients arises. Abdominal wall fat index (AFI), established by Suzuki et al [16] is an indicator of visceral fat deposition and it was thought to reflect metabolic disorders [16]. It can be assessed by ultrasonography (US) in an easy, quick, safe, cheap and reproducible way.

OSAS was also related with increased risk for atherosclerotic diseases [17-20]. Intima-media thickness of common carotid arteries (C-IMT) is a known indicator of cardiovascular risk [21-23] and carotid plaque score (CPS) was also reported as an indicator of cardiovascular risk in a few studies [24,25].

In this study we aimed to reveal whether there is a relation between AFI and presence and/or severity of OSAS. Also, we tried to find whether there is a relation of OSAS with C-IMT and C-PS.

\section{Material and methods}

\section{Participants}

All participants enrolled were selected among the subjects candidate for polysomnography with complaints suggesting OSAS (snoring, daytime somnolance, etc.) from the department of Pulmonary Diseases. The study was reviewed by the Ethical Committee of our institution (decision number: 30/05) before the study. In order to avoid the effects of atherosclerotic and metabolic risk factors other than OSAS the exclusion criteria were smoking, diabetes mellitus, hyperlipidemia and hypertension. Written and signed informed consents were taken from all participants. Age, sex, body mass index (BMI) and waist circumference (WC) of each participant were recorded before US examination. From August 2016 to February 2017, 104 subjects ( 31 females and 73 males, between 23-73 years old) were enrolled.

\section{Ultrasonography}

All US examinations were done by the same radiologist (with 12 years of US experience) within the day before polysomnography, so the radiologist was blind to the AHI values. All examinations were done with the same ultrasound system (Aplio 500 Toshiba Ultrasound Systems, Tokyo, Japan) and with the same linear-array transducers.

\section{Abdominal wall fat index}

Maximum thickness of preperitoneal fat $\left(\mathrm{P}_{\max }\right)$ and minimum thickness of subcutaneous fat $\left(\mathrm{S}_{\min }\right)$ were measured using $10 \mathrm{MHz}$ linear probe and AFI was calculated (AFI $=\mathrm{P}_{\max } / \mathrm{S}_{\min }$ ) [16] (fig 1). The examination was performed in the supine position, and paramedian scanning was done beginning from the xiphoid to the umbilical level, the transducer was kept perpendicularly and touched slightly to avoid compressing fat layers. The subject was asked to hold their breath in order to keep the anterior surface of the left hepatic lobe parallel to the skin [16].

\section{Carotid intima-media thickness}

Examination of bilateral carotid arteries was performed using a $7.5 \mathrm{MHz}$ linear-array transducer. In the supine position, bilateral common and internal carotid arteries were examined for the presence of atherosclerotic plaques, using gray scale and color Doppler modes. C-IMT was defined as the thickness of the hypoechoic layer between the vessel lumen and hyperechoic adventitia [26]. A plaque was defined as a localized increase in the thickness of intima-media more than $1.2 \mathrm{~mm}[26,27]$. C-IMT measurements were done at approximately $1 \mathrm{~cm}$ proximal of the bulb from areas without plaque [26,27] and the average of four values (right near wall, right far wall, left near wall, left far wall) was recorded as C-IMT $\mathrm{Imean}_{\text {}}$ (fig 2).

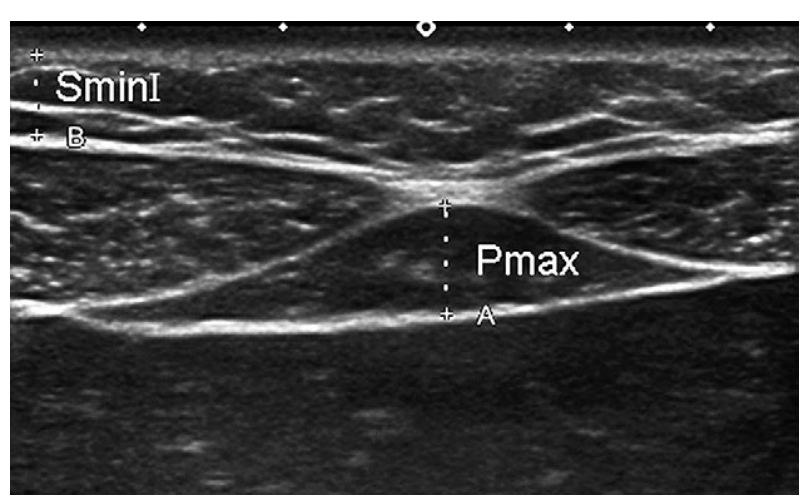

Fig 1. An example to the measurement of maximum thickness of preperitoneal fat $\left(\mathrm{P}_{\max }\right)$ and minimum thickness of subcutaneous fat $\left(\mathrm{S}_{\min }\right)$ in a 28-year-old male subject.

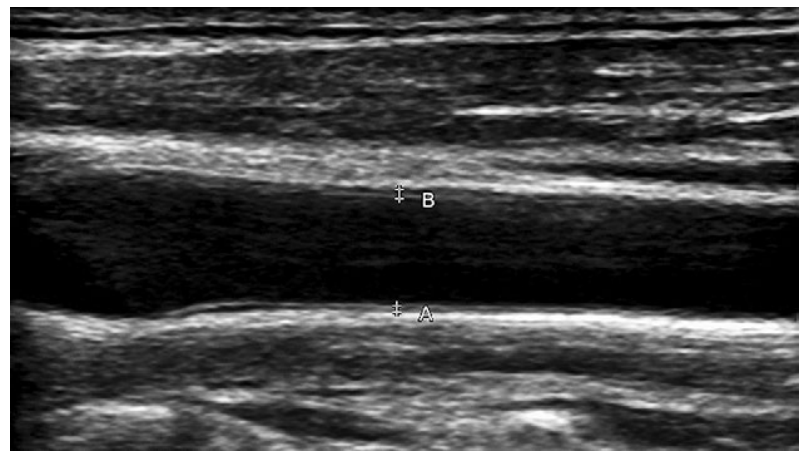

Fig 2. An example to the measurement of carotid intima-media thickness (C-IMT) of a 28 -year-old male subject. C-IMT measurements were done at approximately $1 \mathrm{~cm}$ proximal of the bulb from areas without plaque in the far (A) and near (B) walls of each common carotid artery. 


\section{Carotid plaque score}

For each common carotid artery, the plaque degree was defined as follows: 0 , no plaque; 1 , one plaque thinner than $30 \%$ of the vessel diameter; 2 , one plaque with thickness between $30-50 \%$ of the vessel diameter or multiple plaques thinner than $30 \%$ of the vessel diameter; and 3 , one plaque thicker than $50 \%$ of the vessel diameter or multiple plaques with at least one plaque with thickness between $30-50 \%$ of the vessel diameter [26]. C-PS was recorded as the maximum plaque degree observed on both common carotid arteries.

\section{Polysomnography}

Subjects were grouped according to their AHI values as follows: no OSAS, less than 5; mild OSAS, between 5-15; moderate OSAS, between 15-30; and severe OSAS; more than 30, as previously described [10,13,27].

\section{Statistical analysis}

Statistical analysis of findings was performed by the programme 'SPSS Statistics Base 22.0' (IBM, United States). First, normal distribution of all values was checked using Kolmogorov-Smirnov test, evaluation of skewness and kurtosis and histogram analysis. Secondly, the assessment of the relationship between different parameters was done. Pearson correlation analysis was used to assess the relation of age with AHI, AFI and C-IMT mean $_{\text {; }}$ AHI with BMI, WC, $\mathrm{P}_{\text {max }}, \mathrm{S}_{\min }$ AFI and C$\mathrm{IMT}_{\text {mean }}$ and AFI with C-IMT ${ }_{\text {mean }}$; one way-ANOVA test (analysis of variance) was used to assess the relation of OSAS groups with BMI, WC, AFI and C-IMT ${ }_{\text {mean }}$; C-PS with age and AHI; independent group $t$ test was used to assess relation of OSAS groups with AFI and C-IMT mean; sex with AHI and AFI; Chi Qquire test to assess the relation between OSAS groups and C-PS. $P$ values below 0.05 were accepted to be statistically significant.

\section{Results}

The mean AHI values in male and female subjects were 27.82 and 18.29, respectively and AHI values of
Table I. Relation between the age, ultrasound and polysomnography findings of the study population assessed using Pearson correlation analysis.

\begin{tabular}{lll}
\hline & p value & r value \\
\hline Age - AHI & 0.207 & -0.125 \\
Age - AFI & 0.640 & 0.046 \\
Age - C-IMT $_{\text {mean }}$ & $<0.001$ & 0.514 \\
AHI - BMI & $<0.001$ & 0.382 \\
AHI - WC & $<0.001$ & 0.402 \\
AHI - max $_{\text {AHI - }}$ & $<0.001$ & 0.369 \\
AHI - AFI & 1 & 0 \\
AHI - C-IMT & 0.019 & 0.23 \\
AFI - C-IMT & 0.158 & 0.139 \\
\hline mean & 0.062 & 0.183
\end{tabular}

AHI - apnea-hypopnea index; AFI - abdominal wall fat index; $\mathrm{C}^{-\mathrm{IMT}_{\text {mean }}}$ - mean carotid intima-media thickness; BMI - body mass index; $\mathrm{WC}$ - waist circumference; $\mathrm{P}_{\max }$ - maximum thickness of preperitoneal fat; $\mathrm{S}_{\min }-$ minimum thickness of subcutaneous fat

male subjects were significantly higher than female subjects $(p=0.046)$. There was no significant correlation between age and AHI $(\mathrm{p}=0.207)$. The mean AFI values in male and female subjects were 1.94 and 0.89 , respectively and AFI values of male subjects were also significantly higher than female subjects $(\mathrm{p}<0.001)$.

The relations between the age, US and polysomnography findings of the study population assessed using Pearson correlation analysis are shown in Table I and the relations of OSAS groups with AFI, C-IMT mean $_{\text {and C-PS }}$ in Table II. Although there was no significant difference between OSAS groups in terms of C-IMT $\mathrm{Imean}_{\text {, }} \mathrm{C}$-IMT $\mathrm{IMean}_{\text {m }}$ values of subjects with OSAS (AHI $>5)$ were significantly higher than the subjects withoutOSAS $(\mathrm{AHI}<5)(\mathrm{p}=0.035)$.

There were 76 subjects with C-PS of 0,23 subjects with C-PS of 1, 5 subjects with C-PS of 2 and no subject with C-PS of 3. C-PS was significantly correlated with age $(p<0.001)$ but not with AHI $(p=0.345)$. The relation between AHI and C-PS is shown in Table III.

Table II. The relation of OSAS groups with AFI, C-IMT ${ }_{\text {mean }}$ and C-PS

\begin{tabular}{|c|c|c|c|c|c|}
\hline \multirow{2}{*}{ OSAS } & \multirow{2}{*}{ Mean AFI } & \multirow{2}{*}{ C-IMT mean $_{\text {}}$} & \multicolumn{3}{|c|}{ C-PS (number of subjects) } \\
\hline & & & Score 0 & Score 1 & Score 2 \\
\hline No $(n=18)$ & $1.35 \pm 0.51$ & $0.5 \pm 0.12$ & 14 & 3 & 1 \\
\hline Mild ( $\mathrm{n}=34)$ & $1.64 \pm 1.02$ & $0.59 \pm 0.11$ & 26 & 7 & 1 \\
\hline Moderate $(n=22)$ & $1.45 \pm 0.83$ & $0.57 \pm 0.12$ & 13 & 7 & 2 \\
\hline Severe $(n=30)$ & $1.92 \pm 1.13$ & $0.62 \pm 0.12$ & 23 & 6 & 1 \\
\hline Total $(n=104)$ & $1.63 \pm 0.96$ & $0.59 \pm 0.12$ & 76 & 23 & 5 \\
\hline $\mathrm{p}$ value & 0.179 & 0.099 & & 0.775 & \\
\hline
\end{tabular}

Unless otherwise indicated, data are mean \pm standard deviations. OSAS - obstructive sleep apnea syndrome; AFI - abdominal wall fat index; $\mathrm{C}_{\mathrm{IMT}} \mathrm{IMean}_{\text {mean }}-$ carotid intima-media thickness; C-PS - carotid plaque score 
Table III. Relation between apnea-hypopnea index and carotid plaque score

\begin{tabular}{lll}
\hline C-PS & Mean AHI & p value \\
\hline $0(\mathrm{n}=76)$ & $25.59 \pm 27.03$ & 0.345 \\
$1(\mathrm{n}=23)$ & $23.06 \pm 18.78$ & \\
$2(\mathrm{n}=5)$ & $24.58 \pm 28.05$ & \\
Total $(\mathrm{n}=104)$ & $24.98 \pm 25.28$ & \\
\hline
\end{tabular}

Unless otherwise indicated, data are mean \pm standard deviations. AHI - apnea-hypopnea index; C-PS - carotid plaque score

\section{Discussions}

Previous studies revealed that the severity of OSAS was associated with visceral fat rather than BMI and that visceral fat could be the link between OSAS and metabolic syndrome (MetS) [13,28-30]. Also, it has been reported that visceral obesity contributes to worsening the MetS and OSAS [29,30]. Therefore, early determination of increased visceral fat may lead to early detection of increased risk of worsening of OSAS and the metabolic disorders associated with OSAS. According to our knowledge, this study is the first study dealing with the relation between OSAS and AFI and it revealed that AFI is correlated with AHI. This finding was compatible with the studies that analysed the relation between OSAS and visceral fat $[13,15]$. Besides this, this preliminary result also gives hope about the efficiency of AFI as an indicator of the increased risk of worsening of OSAS and metabolic disorders associated with OSAS.

In most of the studies concerning the relation between OSAS and central obesity, the waist circumference, waist-to-hip ratio or $\mathrm{V} / \mathrm{S}$ ratio (the ratio of visceral fat area to the subcutaneous fat area at umblical level) have been used to determine visceral obesity [12-14]. Tokunaga et al [31] have determined the V/S ratio by computed tomography, in order to appreciate the visceral fat distribution. The determination of AFI using US is easier and practical than the V/S ratio. AFI can be measured by any US device, does not need a special computer programme and a long time for calculation like the V/S ratio. Also, the patients are not exposed to ionizing radiation.

Our study revealed a significant correlation between AHI and AFI but could not demonstrate a statistically significant difference between OSAS groups in terms of AFI. This fact was considered to be due to low numbers of participants in each group. It is obvious that further studies with wider sample sizes are needed to assess the exact relation between severity of OSAS and AFI.

This study revealed that C-IMT mean $_{\text {values of subjects }}$ with OSAS (AHI $>5)$ were significantly higher than the subjects without OSAS $(\mathrm{AHI}<5)$. This finding was also compatible with other studies about the OSAS and CIMT relationship [26,32]. Altın et al [26] revealed that the severity of atherosclerotic plaques of the patients with severe OSAS was higher than the patients with mild OSAS and the subjects without OSAS. Contrary to this study, we could not find any relation between C-PS and OSAS. This could be due to the fact that the subjects with OSAS in our study population were recently diagnosed and do not have any other atherosclerotic risk factor.

There are limitations to this study. The numbers of subjects were low in each group, especially in the group without OSAS $(\mathrm{AHI}<5)$ and there was a striking difference between numbers of subjects in the group without OSAS $(\mathrm{AHI}<5)$ and the groups with OSAS $(\mathrm{AHI}>5)$. This situation was due to the inclusion of only the symptomatic subjects in order to obtain AHI values from all participants; also, we have no control group consisting of asymptomatic subjects for avoiding the unnecessary polysomnographies. Also, all of the subjects with OSAS were diagnosed at the same time as the initiation of the study and they did not have any other atherosclerotic risk factor other than OSAS. This situation encouraged us to investigate the relation between OSAS and C-IMT directly, but at the same time most of the participants had a low-risk for cardiovascular disease. So, it was not surprising that there was no subject with C-PS of 3. Other significant limitations were the lack of agreement analysis and the calculation of the sample sizes. Also, in this preliminary study, the subjects were not classified or selected according to their BMI, WC, menopause status or sex. It will be possible to eliminate most of these limitations by the help of wide-range studies with control groups including follow-up of the patients.

In conclusion, this study demonstrated that AFI increases with the increase of AHI and C-IMT increases in OSAS patients. With its various advantages, AFI may be a new indicator of increased visceral fat and therefore an increased risk of metabolic disorders and worsening of the disease in OSAS patients in the future. To support these findings, wide-range studies including long-term follow-up of OSAS patients are required.

\section{Conflict of interest: none}

\section{References}

1. Malhotra A, White DP. Obstructive sleep apnoea. Lancet 2002;360:237-245.

2. American Academy of Sleep Medicine (AASM). International classification of sleep disorders: diagnostic and coding manual. 2nd ed. Westchester, IL. American Academy of Sleep Medicine; 2005:35-77. 
3. Pillar G, Shehadeh N. Abdominal fat and sleep apnea: the chicken or the egg? Diabetes Care 2008;31 Suppl 2:S303S309.

4. Young T, Palta M, Dempsey J, Skatrud J, Weber S, Badr S. The occurrence of sleep-disordered breathing among middle-aged adults. N Engl J Med 1993;32:1230-1235.

5. Bixler EO, Vgontzas AN, Lin HM, et al. Prevalence of sleep-disordered breathing in women: effects of gender. Am J Respir Crit Care Med 2001;163:608-613.

6. De Backer W. Obstructive sleep apnea/hypopnea syndrome. Panminerva Med 2013;55:191-195.

7. Sleep-related breathing disorders in adults: recommendations for syndrome definition and measurement techniques in clinical research. The Report of an American Academy of Sleep Medicine Task Force. Sleep 1999;22:667-689.

8. Young T, Peppard PE, Taheri S. Excess weight and sleepdisordered breathing. J Appl Physiol (1985) 2005;99:15921599.

9. Schwartz AR, Patil SP, Laffan AM, Polotsky V, Schneider H, Smith PL. Obesity and obstructive sleep apnea: pathogenic mechanisms and therapeutic approaches. Proc Am Thorac Soc 2008;5:185-192.

10. Littner MR, Kushida C, Wise M, et al; Standards of Practice Committee of the American Academy of Sleep Medicine. Practice parameters for clinical use of the multiple sleep latency test and the maintenance of wakefulness test. Sleep 2005;28:113-121.

11. Castaneda A, Jauregui-Maldonado E, Ratnani I, Varon J, Surani S. Correlation between metabolic syndrome and sleep apnea. World J Diabetes 2018;9:66-71.

12. Kono M, Tatsumi K, Saibara T, et al. Obstructive sleep apnea syndrome is associated with some components of metabolic syndrome. Chest 2007;131:1387-1392.

13. Bozkurt NC, Beysel S, Karbek B, Unsal İO, Cakir E, Delibasi T. Visceral Obesity Mediates the Association Between Metabolic Syndrome and Obstructive Sleep Apnea Syndrome. Metab Syndr Relat Disord 2016;14:217-221.

14. Makino S, Handa H, Suzukawa K, et al. Obstructive sleep apnoea syndrome, plasma adiponectin levels, and insulin resistance. Clin Endocrinol (Oxf) 2006;64:12-19.

15. Degache F, Sforza E, Dauphinot V, et al; PROOF Study Group. Relation of central fat mass to obstructive sleep apnea in the elderly. Sleep 2013;36:501-507.

16. Suzuki R, Watanabe S, Hirai Y, et al. Abdominal wall fat index, estimated by ultrasonography, for assessment of the ratio of visceral fat to subcutaneous fat in the abdomen. Am J Med 1993;95:309-314.

17. Lattimore JD, Celermajer DS, Wilcox I. Obstructive sleep apnea and cardiovascular disease. J Am Coll Cardiol 2003;41:1429-1437.

18. Peker Y, Hedner J, Kraiczi H, Löth S. Respiratory disturbance index: an independent predictor of mortality in coronary artery disease. Am J Respir Crit Care Med 2000;162:81-86.

19. Yaggi HK, Concato J, Kernan WN, Lichtman JH, Brass LM, Mohsenin V. Obstructive sleep apnea as a risk factor for stroke and death. N Engl J Med 2005;353:20342041.

20. Yumino D, Tsurumi Y, Takagi A, Suzuki K, Kasanuki H. Impact of obstructive sleep apnea on clinical and angiographic outcomes following percutaneous coronary intervention in patients with acute coronary syndrome. Am J Cardiol 2007;99:26-30.

21. Polak JF, O'Leary DH. Carotid Intima-Media Thickness as Surrogate for and Predictor of CVD. Glob Heart 2016;11:295-312.

22. Naqvi TZ, Lee MS. Carotid intima-media thickness and plaque in cardiovascular risk assessment. JACC Cardiovasc Imaging 2014;7:1025-1038.

23. Ludwig $M$, von Petzinger-Kruthoff A, von Buquoy M, Stumpe KO. Intima media thickness of the carotid arteries: early pointer to arteriosclerosis and therapeutic endpoint. Ultraschall Med 2003;24:162-174.

24. Sutton-Tyrrell K, Wolfson SK Jr, Thompson T, Kelsey SF. Measurement variability in duplex scan assessment of carotid atherosclerosis. Stroke 1992;23:215-220.

25. Sutton-Tyrrell K, Lassila HC, Meilahn E, Bunker C, Matthews KA, Kuller LH. Carotid atherosclerosis in premenopausal and postmenopausal women and its association with risk factors measured after menopause. Stroke 1998;29:1116-1121.

26. Altin R, Ozdemir H, Mahmutyazicioğlu K, et al. Evaluation of carotid artery wall thickness with high-resolution sonography in obstructive sleep apnea syndrome. J Clin Ultrasound 2005;33:80-86.

27. Ozdemir C, Conkbayır I, Kuru A, et al. Correlation between the intima-media thickness and Framingham risk score in patients with sleep apnea syndrome. J Thorac Dis 2013;5:751-757.

28. Oğretmenoğlu O, Süslü AE, Yücel OT, Onerci TM, Sahin A. Body fat composition: A predictive factor for obstructive sleep apnea. Laryngoscope 2005;115:1493-1498.

29. Angelico F, del Ben M, Augelletti T, et al. Obstructive sleep apnoea syndrome and the metabolic syndrome in an internal medicine setting. Eur J Intern Med 2010;21:191-195.

30. Liu KH, Chu WC, To KW, et al. Mesenteric fat thickness is associated with increased risk of obstructive sleep apnoea. Respirology 2014;19:92-97.

31. Tokunaga K, Matsuzawa Y, Ishikawa K, Tarui S. A novel tehnique for the determination of body fat by computed tomography. Int J Obes 1983;7:437-445.

32. Schulz R, Seeger W, Fegbeutel C, et al. Changes in extracranial arteries in obstructive sleep apnoea. Eur Respir J 2005;25:69-74. 